\title{
Human Cell-Based Artificial Antigen Presenting Cells for Use in Natural Killer Cell Adoptive Therapy
}

Keywords: Artificial antigen presenting cell; Adoptive therapy; Cytokine; K562; Natural killer cells

\begin{abstract}
Natural Killer (NK) cells are critical components of the immune system responsible for tumour recognition and eradication. Recent studies of haematopoietic cell transplantation highlighted the utility of NK cell adoptive therapy used to enhance the graft-versus-leukaemia effect without worsening graft-versus-host disease. However, NK cell adoptive therapy is limited by the fact that it is difficult to prepare clinically adequate numbers of NK cells. Artificial antigen presenting cells have been designed and developed as an off-the-shelf strategy to prime NK cell production in vitro; facilitating the production of adequate cell numbers capable of efficiently engrafting, persisting, and responding to tumours in vivo.
\end{abstract}

\section{Abbreviations}

NK: Natural Killer; HCT: Haematopoietic Cell Transplantation; GVHD: Graft-Versus-Host Disease; GVL: Graft-Versus-Leukaemia; PBMCs: Peripheral Blood Mononuclear Cells; EBV-LCL: EpsteinBarr Lymphoblastoid Cell Line; GMP: Good Manufacturing Practice; aAPCs: Artificial Antigen Presenting Cells; CLP: Common Lymphoid Progenitor; NKP: Pre-Nk Cell Precursor; NCR: Natural Cytotoxicity Receptor; ADCC: Antibody-Dependent Cell-Mediated Cytotoxicity; MCMV: Mouse Cytomegalovirus; CMV: Cytomegalovirus; rhIL-2: Recombinant Human Il-2; ICAM-1: Intercellular Adhesion Molecule-1; LFA-3: Lymphocyte Function-Associated-Antigen-3; AML: Acute Myeloid Leukaemia; EWS: Ewing Sarcoma; KIRs: Immunoglobulin-Like Receptors; NCRs: Normal Cytotoxicity Receptors

\section{Introduction}

More than a century ago, the immune system was recognised to be vital in terms of controlling tumour growth [1]. Cancer immunotherapy exploits the intrinsic power of the immune system to fight disease [2]. The goal of cancer immunotherapy is to build persistent and specific immunological "memory" to prevent cancer recurrence [3]. Adoptive cell therapy is a promising means to this end; anti-tumour immune cells can be manipulated in vitro to prepare optimal cell subsets facilitating sustained responses that augment clinical outcomes. Haematopoietic Cell Transplantation (HCT) was the first immune system-based cellular therapy to be developed, and has allowed patients with haematological cancers to enjoy long-term disease-free survival [4]. However, acute Graft-Versus-Host Disease (GVHD) remains a common, unpredictable, and severe inflammatory complication in patients undergoing HCT. Over the past decade, clinical and translational researchers have sought to use NK cells

\section{Journal of}

Cytology \& Molecular Biology

\section{Yaojun Peng* \\ Cancer Center Key Laboratory, General Hospital of PLA, China}

*Address for Correspondence

Yaojun Peng, 28 FuXing Road, Cancer Center Key Laboratory, General Hospital of PLA, Beijing, 100853, China, Tel: +86-10-66937592; Fax: +8610-66936407; E-mail: pengyaojun@yeah.net

Submission: 03 August, 2017

Accepted: 29 August, 2017

Published: 04 September, 2017

Copyright: ๑ 2017 Peng Y. This is an open access article distributed under the Creative Commons Attribution License, which permits unrestricted use, distribution, and reproduction in any medium, provided the original work is properly cited.

to enhance the Graft-Versus-Leukaemia (GVL) effect without worsening GVHD [5,6]. Clinical trials of the efficacy and safety of NK cell adoptive therapy in patients undergoing HCT are currently underway [7]. When preparing NK cells for use in adoptive therapy, large numbers of such cells must be endowed with the capacities to efficiently engraft, persist, and respond to the tumour in vivo.

Originally, feeder cell lines including Peripheral Blood Mononuclear Cells (PBMCs), RPMI8866 cells, an Epstein-Barr Lymphoblastoid Cell Line (EBV-LCL), and K562 cells were used to propagate NK cells in vitro [8]. However, the numbers of homogeneous NK cells thus created were inadequate to meet the needs of clinical trials. For example, B lymphoblastoid cells were used as feeders stimulating human PBMCs, but the NK cell numbers rose only 25 -fold and the $\mathrm{T}$ cell numbers about 3 -fold. Thus, the elimination of $\mathrm{CD} 3+/$ $\mathrm{CD} 5+\mathrm{T}$ cells to obtain purer preparations of NK cells was required to reduce the risk of GVHD induced by T cell contamination [9]. In compliance with established Good Manufacturing Practice (GMP), Artificial Antigen Presenting Cells (aAPCs) have been designed and developed as a highly efficient off-the-shelf strategy to generate NK cells in vitro. In this review, we focus on recent advances in the use of K562-based aAPCs to stimulate NK cell propagation; this may yield effective adoptive cell therapies for cancer.

Our study is a review article, which is not involved the ethical approval of ethics committee and informed consent of patients.

\section{Phenotypic and functional properties of NK cells}

NK cells are large granular lymphocytes that are classified as innate immune cells [10]. Unlike T and B cells, NK cells can lyse certain malignant cells and pathogens in an antigen-independent manner [11]. Continual research into the development and function of NK cells has revealed that these cells straddle the line between innate and adaptive immunity and play important roles in controlling infection, autoimmunity, and tumour immune surveillance [11-13].

NK cells are thought to be derived from, and to develop primarily in, bone marrow $[10,14]$. The cells are not static during development and maturation; the expression of a variety of cell surface molecules is stimulated or inhibited in a particular order during different 
developmental stages. Relevant stages include Common Lymphoid Progenitor (CLP), Pre-Nk Cell Precursor (NKP), NKP, immature NK, and mature NK cells (Figure 1) [10]. Mature human NK cells do not express CD3, but they do express CD56 and they can be subdivided into CD56 $6^{\text {bright }}$ and $\mathrm{CD} 56^{\mathrm{dim}}$ subsets with different functional properties $[13,15]$. In contrast, murine NK cells do not express CD56, and it has thus been suggested that NKp46, a highly conserved member of the Natural Cytotoxicity Receptor (NCR) family of NK-activating receptors [16], might be a useful cross-species biomarker of NK cells $[12,17]$. CD3-CD56 $6^{\text {bright }} \mathrm{NKp} 46^{\text {bright }} \mathrm{NK}$ cells produce large amounts of cytokines and chemokines when activated, but this NK cell subset exerts minimal cytolytic functions [18]. The CD3-CD56 dim NKp46 dim population is terminally differentiated from the younger CD56 bright population, and effectively lyses tumour cell targets [13,19]. Also, the former cells express high levels of the low-affinity Fc receptor for IgG (CD16), which mediates Antibody-Dependent Cell-Mediated Cytotoxicity (ADCC) [20].

Recently, it was shown that, like T and B cells, NK cells exhibit several features of adaptive immunity when exposed to proinflammatory cytokines or viral infections $[10,19,21]$. Romee $R$ et al. showed that brief pre-activation with combinations of cytokines, including IL-12, IL-15, and IL-18, followed by a 7- to 21-day rest, induced extensive proliferation of memory-like NK cells exhibiting enhanced IFN- $\gamma$ production after re-stimulation; this capacity was maintained even after several rounds of cell division [22]. Low concentrations of IL-2, synthesized either by autologous $\mathrm{T}$ cells or exogenously administered, were essential to promote NK cell function and proliferation in vivo [23].

Work with a Mouse Cytomegalovirus (MCMV)-infected model, in which $\mathrm{Ly} 49 \mathrm{H}+\mathrm{NK}$ cells were adoptively transferred into mice lacking the $\mathrm{Ly} 49 \mathrm{H}$ receptor, revealed that MCMV infection selectively drove the expansion of a long-lived pool of "memory" Ly49H+ cells [24]. Signaling by IL-12 and STAT4, but (surprisingly) not IFN- $\gamma$, was essential for the development of NK cell "memory" [25]. NKG2C forms a heterodimer with CD94 on the NK cell surface [26]. Human CD56dimCD57+NKG2C+ NK cells thus resemble Ly49H+ memorylike NK cells in many respects [27], and it is accepted that such cells are adaptive NK cells induced by Cytomegalovirus (CMV) infection in humans [28]. Lönnqvist B et al. were the first to report that early
CMV reactivation protected against the relapse of haematologic cancer in patients undergoing HCT [29]. Follow-up data on the associations between the levels of CMV-induced adaptive NK cells and the extent of relapse have varied by both patient cohort and transplant centre; further work is required [30].

Moreover, previous studies have investigated the antineoplastic effect of allogeneic NK cells in solid tumors. However, immunoglobulin-like receptors (KIRs) mismatched allogeneic NK cells might lead to immune-mediated rejection due to MHC mismatch. The study of Schaffer $\mathrm{M}$ et al. reported that donor-derived, alloreactive NK cells may interfere with immunity to infection in the early posttransplantation period [31]. A review article found no advantage of KIR ligand incompatibility on outcomes of unrelated donor bone marrow transplantations [32]. In the study of Igarashi $\mathrm{T}$ et al. they showed that KIR-incompatible allogeneic NK cells were more cytotoxic to tumor targets than their KIR ligand-matched counterparts [33].

In general, a developmental continuum is evident as CLP cells mature into NK cells, and when activated effectors become longlived memory NK cells. Selective propagation of appropriate subpopulations of NK cells exhibiting desired functions may greatly improve the efficacy of adoptive therapy. It is essential to understand phenotypic and functional changes associated with the development of NK cells if it is desired to use such cells for immunotherapeutic purposes.

\section{Cytokines used to expand NK cell populations}

Cytokines aid in NK cell expansion prior to the application of adoptive immunotherapy; these materials enhance NK cell antitumour activity. The cytokines IL-2, IL-12, IL-15, IL-18, and IL-21 regulate human NK cell development, activation, survival, and function (Table 1) [34-39].

Below, we briefly review the basic biology of IL-2 and IL-15 in the context of NK cell adoptive therapy. IL-2 and IL-15 have been intensively studied, and exert similar biological activities [40]. IL-2 is produced by activated T cells [41], and IL-15 is generated by various APCs [42]. Both cytokines use IL-2/15R $\beta$ and $\gamma$ c receptor components when transmitting intracellular signals activating the downstream Jak1/3, STAT3/5, PI3K, and MAPK pathways, and, ultimately NF- $\kappa B$

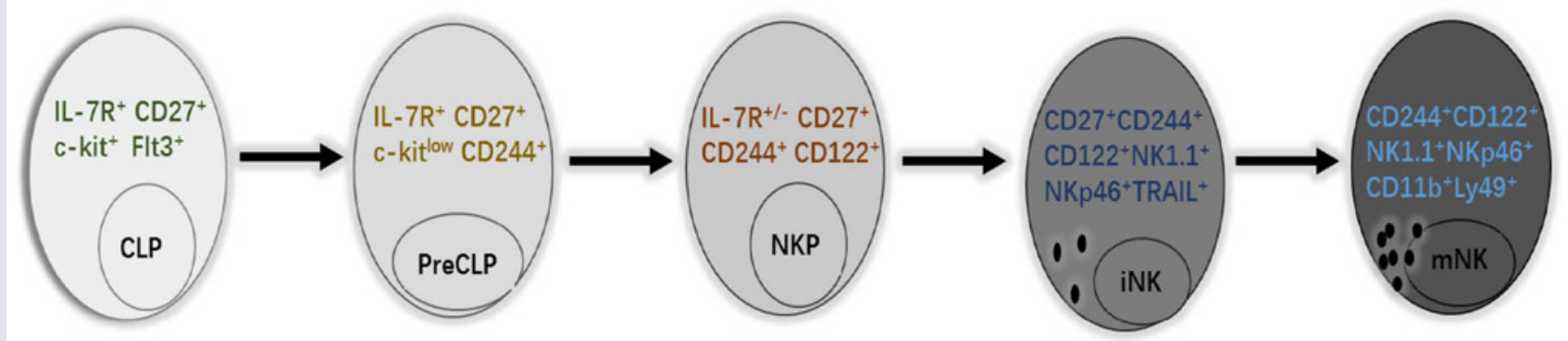

Figure 1: Stages of NK cell development. NK cells are derived from the CLP which is characterized by its expression of IL-7R $\mathrm{C}-\mathrm{kit}$ and Flt3. They further develop into preNKP distinguished from the NKP by its expression of IL-7R and losing expression of CD122. Immature NK cells begin to express specific NK cell markers NK1.1 and NKp46, and as they further mature. They express CD11b and Ly49 while lack of CD27 expression, acquire cytotoxic capacities and secrete cytokines such as IFN-y. 
Table 1: Key cytokines regulating human NK cells.

\begin{tabular}{|c|c|c|c|}
\hline Cytokine & Source & $\begin{array}{l}\text { Receptor and } \\
\text { components } \\
\text { thereof }\end{array}$ & Functions \\
\hline IL-2R & $\mathrm{T}$ cells & $\begin{array}{l}\text { IL-2Ra } \\
\text { IL-2/15R } \beta \\
\text { yc }\end{array}$ & $\begin{array}{l}\text { Induces in/ex vivo activation, maintains } \\
\text { in vitro survival [33,34], enhances } \\
\text { cytotoxic function, and upregulates IL- } \\
12 \text { production [35] }\end{array}$ \\
\hline IL-12R & $\begin{array}{l}\mathrm{DC} \\
\mathrm{M} \varphi\end{array}$ & $\begin{array}{l}\text { IL-12Rb1 } \\
\text { IL-12Rb2 }\end{array}$ & $\begin{array}{l}\text { Induces cell activation, promotes cell } \\
\text { proliferation and differentiation, and } \\
\text { enhances cellular cytotoxic activity and } \\
\text { IFN-y production }[34,36]\end{array}$ \\
\hline IL-15R & $\begin{array}{c}\mathrm{DC} \\
\mathrm{M} \varphi \\
\mathrm{BM} \\
\text { stroma }\end{array}$ & $\begin{array}{l}\text { IL-15Ra } \\
\text { IL-2/15R } \beta \\
\text { yc }\end{array}$ & $\begin{array}{c}\text { Promotes in vitro cell proliferation, } \\
\text { survival, maturation, and activation } \\
\qquad[35,37]\end{array}$ \\
\hline IL-18R & $\begin{array}{l}\mathrm{DC} \\
\mathrm{M} \varphi\end{array}$ & $\begin{array}{l}\text { IL-18Ra/R1 } \\
\text { IL-18Rß/RAP }\end{array}$ & $\begin{array}{l}\text { Augments cell maturation and promotes } \\
\text { IFN-y synthesis [37] }\end{array}$ \\
\hline IL-21R & $\mathrm{T}$ cell & $\begin{array}{c}\text { IL-21R } \\
\text { Yc }\end{array}$ & $\begin{array}{c}\text { Enhances cellular proliferative } \\
\text { and cytotoxic activities; increases } \\
\text { expression of IFN- }- \text {, perforin, and } \\
\text { granzyme B [33] }\end{array}$ \\
\hline
\end{tabular}

† BM: bone marrow

$\ddagger D C$ : dendritic cell

$\S \mathrm{M \varphi}$ : macrophagocyte

[35]. Thus, when the two pathways triggered by IL-2 and IL-15 are activated in NK cells, the functional effects are similar [43]. When the cytokines bind to receptors on NK cells, both transduce positive signals important in terms of NK cell development, proliferation, homeostasis, cytokine production, and cytotoxicity [44].

Based on a profound understanding of the fundamental biology of IL-2, Koehl U et al. developed a GMP-compliant NK cell isolation and expansion protocol for the clinical preparation of highly enriched IL-2-stimulated NK cells, and infused these into three paediatric leukaemia patients undergoing haploidentical stem cell transplantation [45]. During recombinant human IL-2 (rhIL-2) stimulation in vitro, NK cell numbers fell over the first 5 days but then recovered to attain $98 \%$ viability. By day 14 , the median expansion was only 5 -fold. However, subsequent studies on the role played by IL-2 in regulatory T cell function showed that IL-2 also activated CD4+CD25+Foxp3+ regulatory $\mathrm{T}$ cells, which are known to negatively regulate NK and effector T cells [46]. Moreover, the effects of different doses of IL-2 given to patients after an infusion of NK cells have been investigated in several clinical studie $[47,48]$. Treatment with a low dose of IL-2 in vivo had no obvious effect, whereas a high dose caused severe systemic toxicity $[47,49]$. Hence, clinical interest in cytokines other than IL-2 resurged when several studies yielded further insight into the various ways in which IL-15 acted on NK cells [50]. Berger $\mathrm{C}$ et al. showed in nonhuman primates that IL-15 expanded NK cell numbers and those of memory CD8+ and CD4+ $\mathrm{T}$ cells in peripheral blood, with minimal increases in regulatory $\mathrm{T}$ cells [51]. Also, IL-15 clearance between doses was achieved by intermittent administration of the cytokine. It was suggested that such a regimen should be clinically considered to mitigate possible toxicity caused by IL- 15 .

\section{Non-aAPC approaches toward NK cell expansion}

To date, the main source of NK cells for adoptive therapy is peripheral blood [52]. Umbilical cord blood, bone marrow, human embryonic stem cells, and induced pluripotent stem cells also generate NK cells at different yields [53-55]. Efficient infusion requires a large number of NK cells, typically $5 \times 10^{6}$ to $5 \times 10^{7} /$ $\mathrm{kg}$ body weight [49], but NK cells constitute only about $10 \%$ of peripheral blood lymphocytes 18 . Moreover, as NK cells normally do not exhibit persistent proliferation when responding to tumours after in vivo infusion [56], many researchers have sought to generate high numbers of functional NK cells in vitro.

In line with GMP, NK cells are obtained by leukapheresis of peripheral blood followed by the depletion of $\mathrm{CD} 3+\mathrm{T}$ cells, with or without subsequent enrichment of CD56+ cells to obtain pure NK cell products [57]. After one or two rounds of selection, the cells are conventionally incubated with IL-2 overnight and infused the following day [57]. By this means, NK cells are expanded only 5 -fold in number after 2 weeks of stimulation but exhibit potent lytic activity [58]. Activated autologous $\mathrm{T}$ cells may facilitate NK cell expansion, probably by releasing stimulatory cytokines such as IL-2 [59]. However, the acquisition of autologous T cells is laborious, slow, and expensive, rendering it impractical to expand NK cells using autologous T cells. Beads coated with NKp46 and $\mathrm{CD} 2$ are commercially available, rendering it possible to expand $\mathrm{NK}$ cell populations 100 -fold in 21 days [60]. However, it is important to ensure that the beads are detached from the expanded NK cells before infusion to prevent micro-embolic complications and the development of immune responses to the linked monoclonal antibodies [61].

\section{K562 cells as a platform for human cell-based aAPCs}

K562 is a human erythroleukaemic cell line isolated from a patient with chronic myelogenous leukaemia who was in blastic crisis $[3,62]$. These cells were initially selected as a platform for $\mathrm{T}$ cells expansion because the cells presented antigens to, and expanded, $\mathrm{T}$ cells in vitro, and were safe in humans. Also, the cells do not express endogenous HLA molecules, which can induce allospecific T cells. Finally, the cells constitutively express co-stimulatory molecules, including intercellular adhesion molecule-1 (ICAM-1, CD54) and lymphocyte function-associated-antigen-3 (LFA-3, CD58); these molecules facilitate T cell activation [63,64]. K562 cells are known targets of NK cells. K562 cells ectopically expressing NK cell genes (co-stimulatory molecules and cytokines) effectively propagate both NK cells and T cells. Therefore, K562-derived aAPCs serve as excellent stimulators of NK cells [3].

\section{aAPCs for NK cell expansion}

K562-based aAPCs were initially manipulated to generate tumour-specific $\mathrm{T}$ cells for the treatment of haematological cancers $[64,65]$. The cells were transduced with genes encoding various molecules allowing them to simulate professional APCs during $\mathrm{T}$ cell activation61. Several preclinical studies of haematological malignancies showed that NK cells facilitated engraftment and augmented GVL without mediating GVHD [64,66]; aAPCs have also been utilised in NK cell adoptive therapy to expand the numbers of clinical-grade NK cells (Table 2) [67-71].

Fujisaki $\mathrm{H}$ et al. were the first to transduce K562 cells with membrane-bound IL-15 and 4-1BB in an effort to stimulate PBMCs toward the creation of large numbers of NK cells in vitro [71]. Highly 
Table 2: Expansion of NK cells in vitro for clinical use.

\begin{tabular}{|c|c|c|c|c|c|c|}
\hline $\begin{array}{l}\text { Source of } \\
\text { NK cell }\end{array}$ & K562-based aAPC & Additional cytokines & Mean fold proliferation & Purity & Phenotype & Reference \\
\hline $\begin{array}{c}\text { CD3-CD56 }{ }^{+} \\
\text {cells from PBMCs }\end{array}$ & K562-mb15-41BBL & IL-2 & $\begin{array}{c}90.5 \\
\text { in } 7 \text { days }\end{array}$ & $83 \%$ & $\begin{array}{c}\mathrm{CD}^{-}, \mathrm{CD}^{+}{ }^{+} \\
\mathrm{NKG}^{+} \mathrm{D}^{+}, \mathrm{NCRs}^{+}\end{array}$ & [67] \\
\hline PBMCs & K562-mb15-41BBL & IL-2 & $\begin{array}{c}209 \\
\text { in } 8-10 \text { days }\end{array}$ & $61 \%$ & $\mathrm{CD}^{-}, \mathrm{CD}^{\circ} 6^{+}$ & [68] \\
\hline PBMCs & K562-mb21-41BBL & IL-2 & $\begin{array}{r}4,7967 \\
\text { in } 21 \text { days }\end{array}$ & $78 \%$ & $\begin{array}{c}\mathrm{CD}^{-}, \mathrm{CD}^{+} 6^{+}, \mathrm{CD}^{+} 6^{+} \\
\mathrm{NKG}^{+}, \mathrm{NCRs}^{+} \\
\mathrm{CD}^{+} 60^{+}\end{array}$ & [69] \\
\hline PBMCs & $\begin{array}{c}\text { K562-mb15-MICA- } \\
\text { 41BBL }\end{array}$ & None & $\begin{array}{c}550 \\
\text { in } 24 \text { days }\end{array}$ & $86 \%$ & $\begin{array}{c}\mathrm{CD}^{-} \\
\mathrm{CD}^{-} 6^{+} \\
\mathrm{CD}^{+} 6^{+} \\
\mathrm{CD}^{+} 7^{+}, \mathrm{NKG}^{+} \mathrm{D}^{+} \\
\mathrm{NKP}^{+} 6^{+}, \mathrm{CXCR}^{+}\end{array}$ & [70] \\
\hline $\begin{array}{l}\text { CD3cells from UCB } \\
\text { mononuclear cells }\end{array}$ & K562-mb21-41BBL & IL-2 & $\begin{array}{c}1848 \\
\text { in } 14 \text { days }\end{array}$ & $>95 \%$ & $\begin{array}{c}\text { CD3- } \\
\text { CD56 }^{+} \\
\text {CD16 }^{+} \\
\text {NKG2D }^{+} \\
\text {NCRs }^{+}\end{array}$ & [71] \\
\hline
\end{tabular}

† PBMCs: peripheral blood mononuclear cell

$\ddagger$ UCB: umbilical cord blood

cytotoxic NK cells underwent up to 30 doublings; expansion was probably limited by telomere attrition, as suggested by the extent of immortalisation of TERT-transduced NK cells [71]. A pre-clinical study showed that NK cells expanded by K562-mb15-41BBL cells effectively killed primary acute myeloid leukaemia (AML) cells from AML patients, and AML cell lines in vitro. Furthermore, in a xenogeneic AML model, the expanded NK cells effectively suppressed the growth of leukaemic cells and remained detectable even to day 31 after the systemic administration of a high dose of IL-2 [56]. Preclinical studies of paediatric patients with solid tumours showed that NK cells expanded by K562-mb15-41BBL cells effectively killed Ewing sarcoma (EWS) and rhabdomyosarcoma cell lines, and eradicated EWS cells engrafted into mice that were not obese but were both diabetic and exhibited severe IL-2 immunodeficiency (the IL-2R $\gamma^{\text {null }}$ mouse line) [72]. Theoretical and practical bases for the large-scale ex vivo expansion of NK cells via aAPCs have thus been established.

The findings of Fujisaki $\mathrm{H}$ et al. have been further confirmed; Zhang $\mathrm{H}$ et al. utilized aAPCs expressing CD137L and IL-15Ra to activate and expand peripheral blood NK cell populations (CD137L/ IL-15 NK cells) by up to 1,000-fold in 3 weeks, expanded NK cells by these aAPCs exhibited an evident increase in the expression levels of KIRs and normal cytotoxicity receptors (NCRs: NKp30, NKp44, and NKp46) that have been suggested to be promising biomarkers of the potency of NK cells [71,73]. Additionally, K562-MICA-4-1BBLIL-15 expressing aAPC stimulated NK cells to expand by a mean of 550 -fold over approximately 3 weeks, and they promoted NK cell activation, proliferation, and cytotoxicity [69].

To deal with the fact that telomere shortening in K562-mb1541BBL-expanded NK cells limited cellular propagation, Singh $\mathrm{H}$ et al. transduced mbIL-21 into K562 cells expressing CD64, CD86, 4-1BBL, and truncated CD19 (Clone9.mbIL21). Compared to cells expressing mbIL-15, mbIL-21-expressing aAPCs more potently promoted NK cell expansion in the absence of any sign of cellular demise [74]. NK cells expanded using mbIL-21 were phenotypically similar to those expanded using mbIL-15, but secreted more cytokines. The enhanced killing exhibited by mbIL-21-expanded NK cells was primarily attributable to ADCC $[3,69,75]$.

\section{Conclusion}

Chimeric antigen receptor-modified $\mathrm{T}$ cells have been successfully used to treat B cell malignancies and a number of solid tumours, highlighting the utility of cellular immunotherapy for cancers. Apart from T cells, NK cells that recognise and kill malignant transformed cells in the absence of prior sensitization are optimal candidates for adoptive cellular immunotherapy. Allogeneic stem cell transplantation after the transfusion of KIR-mismatched NK cells is effective for the treatment of patients with haematological cancers. Studies of the NK cell biology underlying the regulation of phenotype and function have yielded inspiring results; it is now possible to manipulate optimal subsets of NK cells for the purpose of adoptive immunotherapy. It is encouraging that only 5 years have elapsed from the discovery of cytokine induced memory-like NK cells to translational clinical testing of their efficacy and safety in humans.

The in vitro preparation of appropriately activated and expanded NK cell populations is difficult but important (Figure 2). K562-derived aAPCs can be used to generate NK cells in numbers adequate to meet clinical demands. Also, this approach facilitates the ex vivo study of NK cell development. However, caution should be taken when analyzing aAPC-derived data. During NK cell expansion, phenotypic and functional changes may significantly influence the ultimate efficacy of NK cell adoptive immunotherapy, even though the aAPC approach creates high numbers of activated NK cells. For example, NK cells expanded by K562-mb15-41 BBL aAPCs exhibited replicative demise (a sign of senescence); such cells may be compromised in vivo despite the fact that they efficiently lysed tumour targets in vitro. Therefore, younger NK cells may exhibit better anti-tumour potential than cells subjected to long-term culture and expansion.

In conclusion, as our understanding of human NK cell biology increases, the clinical indications for, and the spectrum of cancers treatable by, NK cells will increase. We expect that advances in our understanding of NK cell biology will create new strategies allowing us to win the battle against cancer.

\section{References}




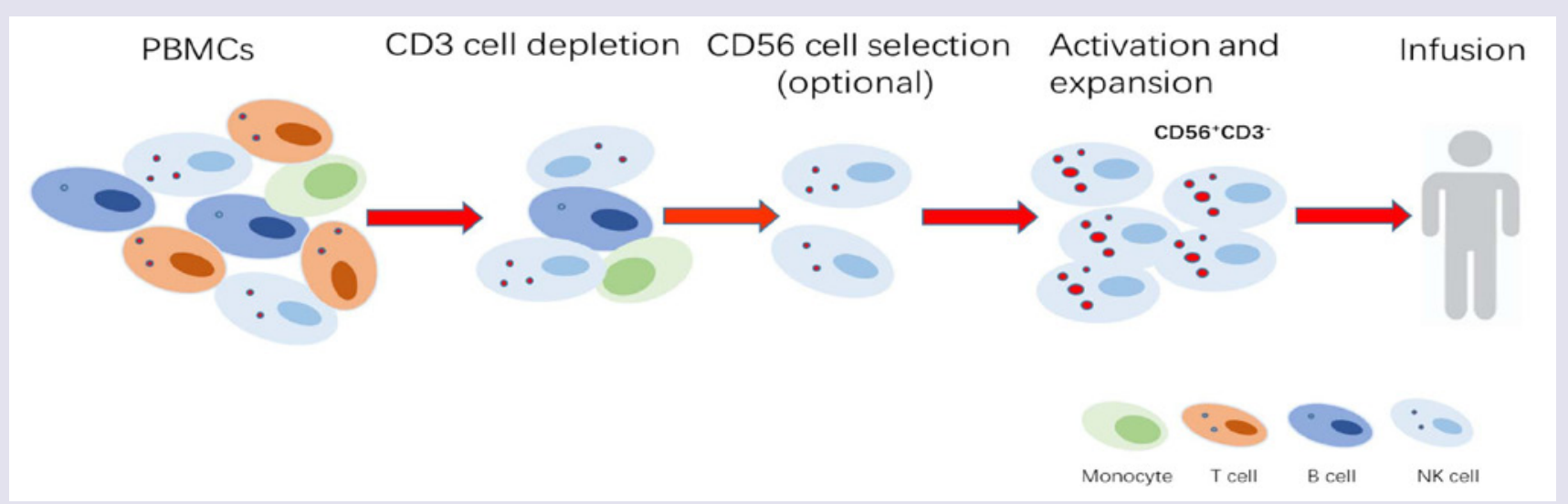

Figure 2: Ex vivo production of NK cells for use in adoptive immunotherapy. Peripheral blood is the principal source of NK cells. NK cells may be enriched by apheresis of PBMCs followed by the depletion of $\mathrm{CD}^{+} \mathrm{T}$ cells. Further secondary selection of CD56 $6^{+}$cells ensures a purer NK cell population. After in vitro activation and expansion, NK cells can be infused into patients undergoing adoptive immunotherapy.

1. Fridman WH, Pages F, Sautes-Fridman C, Jérôme G (2012) The immune contexture in human tumours: impact on clinical outcome. Nat Rev Cancer 12: $298-306$.

2. Lizee G, Overwijk WW, Radvanyi L, Gao J, Sharma P, et al. (2013) Harnessing the power of the immune system to target cancer. Annu Rev Med 64: 71-90.

3. Butler MO, Hirano N (2014) Human cell-based artificial antigen-presenting cells for cancer immunotherapy. Immunol Rev 257: 191-209.

4. Berrien-Elliott MM, Romee R, Fehniger TA (2015) Improving natural killer cell cancer immunotherapy. Curr Opin Organ Transplant 20: 671-680.

5. Koehl U, Brehm C, Huenecke S, Zimmermann SY, Kloess S, et al. (2013) Clinical grade purification and expansion of NK cell products for an optimized manufacturing protocol. Front Oncol 3: 118.

6. Miller JS (2013) Therapeutic applications: natural killer cells in the clinic Hematology. American Society of Hematology. The Education Program 2013: $247-253$

7. Passweg JR, Koehl U, Uharek L, Meyer-Monard S, Tichelli A (2006) Naturalkiller-cell-based treatment in haematopoietic stem-cell transplantation. Best Pract Res Clin Haematol 19: 811-824.

8. Phan MT, Lee SH, Kim SK, Cho D (2016) Expansion of NK cells using genetically engineered K562 feeder cells. Methods Mol Biol 1441: 167-174.

9. Perussia B, Ramoni C, Anegon I, Cuturi MC, Faust J, et al. (1987) Preferentia proliferation of natural killer cells among peripheral blood mononuclear cells cocultured with B Iymphoblastoid cell lines. Nat Immun Cell Growth Regul 6: 171-188.

10. Geiger TL, Sun JC (2016) Development and maturation of natural killer cells Curr Opin Immunol 39: 82-89.

11. Vivier E, Tomasello E, Baratin M, Walzer T, Ugolini S (2008) Functions of natural killer cells. Nat Immunol 9: 503-510.

12. Caligiuri MA (2008) Human natural killer cells. Blood 112: 461-469.

13. Chester C, Fritsch K, Kohrt HE (2015) Natural killer cell immunomodulation: targeting activating, inhibitory, and co-stimulatory receptor signaling for cancer immunotherapy. Front Immunol 6: 601.

14. Rosmaraki EE, Douagi I, Roth C, Colucci F, Cumano A, et al. (2001) Identification of committed NK cell progenitors in adult murine bone marrow. Eur J Immunol 31: 1900-1909.

15. Cooper MA, Fehniger TA, Caligiuri MA (2001) The biology of human natural killer-cell subsets. Trends Immunol 22: 633-640.

16. Sivori S, Vitale M, Morelli L, Sanseverino L, Augugliaro R, et al. (1997) p46, a novel natural killer cell-specific surface molecule that mediates cell activation. J Exp Med 186: 1129-1136.

17. Walzer T, Jaeger S, Chaix J, Vivier E (2007) Natural killer cells: from CD3(-) NKp46(+) to post-genomics meta-analyses. Curr Opin Immunol 19: 365-372.

18. Cooper MA, Fehniger TA, Turner SC, Chen KS, Ghaheri BA, et al. (2001) Human natural killer cells: a unique innate immunoregulatory role for the CD56(bright) subset. Blood 97: 3146-3151

19. Min-Oo G, Kamimura Y, Hendricks DW, Nabekura T, Lanier LL (2013) Natural killer cells: walking three paths down memory lane. Trends Immuno 34: $251-258$

20. Ljunggren HG, Malmberg KJ (2007) Prospects for the use of NK cells in immunotherapy of human cancer. Nat Rev Immunol 7: 329-339.

21. Berrien-Elliott MM, Wagner JA, Fehniger TA (2015) Human cytokine-induced memory-like natural killer cells. J Innate Immun 7: 563-571.

22. Romee R, Schneider SE, Leong JW, Chase JM, Keppel CR, et al. (2012) Cytokine activation induces human memory-like NK cells. Blood 120: 47514760.

23. Leong JW, Chase JM, Romee R, Schneider SE, Sullivan RP, et al. (2014) Preactivation with IL-12, IL-15, and IL-18 induces CD25 and a functional highaffinity IL-2 receptor on human cytokine-induced memory-like natural killer cells. Biol Blood Marrow Transplant 20: 463-473.

24. Sun JC, Beilke JN, Lanier LL (2009) Adaptive immune features of natura killer cells. Nature 457: 557-561.

25. Sun JC, Madera S, Bezman NA, Beilke JN, Kaplan MH, et al. (2012) Proinflammatory cytokine signaling required for the generation of natural killer cell memory. J Exp Med 209: 947-954

26. Braud VM, Allan DS, O'Callaghan CA, Söderström K, D’Andrea A, et al. (1998) HLA-E binds to natural killer cell receptors CD94/NKG2A, B and C. Nature 391: 795-799.

27. Arase H, Mocarski ES, Campbell AE, Hill AB, Lanier LL (2002) Direct recognition of cytomegalovirus by activating and inhibitory NK cell receptors. Science 296: 1323-1326.

28. Guma M, Budt M, Saez A, Brckalo T, Hengel H, et al. (2006) Expansion of CD94/NKG2C+ NK cells in response to human cytomegalovirus-infected fibroblasts. Blood 107: 3624-3631.

29. Lonnqvist B, Ringden O, Ljungman P, Wahren B, Gahrton G (1986) Reduced risk of recurrent leukaemia in bone marrow transplant recipients after cytomegalovirus infection. Br J Haematol 63: 671-679. 
30. Cichocki F, Verneris MR, Cooley S, Bachanova V, Brunstein CG, et al. (2016) The past, present, and future of nk cells in hematopoietic cell transplantation and adoptive transfer. Curr Top Microbiol Immunol 395: 225-243.

31. Schaffer M, Malmberg KJ, Ringden O, Ljunggren HG, Remberger M (2004) Increased infection-related mortality in KIR-ligand-mismatched unrelated allogeneic hematopoietic stem-cell transplantation. Transplant 78: 10811085 .

32. Davies SM, Ruggieri L, DeFor T, Wagner JE, Weisdorf DJ, et al. (2002) Evaluation of KIR ligand incompatibility in mismatched unrelated donor hematopoietic transplants. Killer immunoglobulin-like receptor. Blood 100: 3825-3827.

33. Igarashi T, Wynberg J, Srinivasan R, Becknell B, McCoy JP Jr, et al. (2004) Enhanced cytotoxicity of allogeneic NK cells with killer immunoglobulin-like receptor ligand incompatibility against melanoma and renal cell carcinoma cells. Blood 104: 170-177.

34. Yoon SR, Kim TD, Choi I (2015) Understanding of molecular mechanisms in natural killer cell therapy. Exp Mol Med 47: e141.

35. Romee R, Leong JW, Fehniger TA (2014) Utilizing cytokines to functionenable human NK cells for the immunotherapy of cancer. Scientifica (Cairo) 2014: 205796.

36. Loza MJ, Zamai L, Azzoni L, Rosati E, Perussia B (2002) Expression of type 1 (interferon gamma) and type 2 (interleukin-13, interleukin-5) cytokines at distinct stages of natural killer cell differentiation from progenitor cells. Blood 99: 1273-1281.

37. Sutlu T, Alici E (2009) Natural killer cell-based immunotherapy in cancer: current insights and future prospects. J Intern Med 266: 154-181.

38. Robertson MJ, Cameron C, Lazo S, Cochran KJ, Voss SD, et al. (1996) Costimulation of human natural killer cell proliferation: role of accessory cytokines and cell contact-dependent signals. Nat Immun 15: 213-226.

39. Pittari G, Filippini P, Gentilcore G, Grivel JC, Rutella S (2015) Revving up natural killer cells and cytokine-induced killer cells against hematological malignancies. Front Immunol 6: 230.

40. Waldmann TA (2006) The biology of interleukin-2 and interleukin-15 implications for cancer therapy and vaccine design. Nat Rev Immunol 6: 595601.

41. Fehniger TA, Cooper MA, Nuovo GJ, Cella M, Facchetti F, et al. (2003) CD56bright natural killer cells are present in human lymph nodes and are activated by $\mathrm{T}$ cell-derived IL-2: a potential new link between adaptive and innate immunity. Blood 101: 3052-3057.

42. Newman KC, Riley EM (2007) Whatever turns you on: accessory-celldependent activation of NK cells by pathogens. Nat Rev Immunol 7: 279-291.

43. Becknell B, Caligiuri MA (2005) Interleukin-2, interleukin-15, and their roles in human natural killer cells. Adv Immunol 86: 209-239.

44. Fehniger TA, Cooper MA, Caligiuri MA (2002) Interleukin-2 and interleukin-15: immunotherapy for cancer. Cytokine Growth Factor Rev 13: 169-183.

45. Koehl U, Sorensen J, Esser R, Zimmermann S, Grüttner HP, et al. (2004) IL-2 activated NK cell immunotherapy of three children after haploidentical stem cell transplantation. Blood Cells Mol Dis 33: 261-266.

46. Malek TR, Castro I (2010) Interleukin-2 receptor signaling: at the interface between tolerance and immunity. Immunity 33: 153-165.

47. Rosenberg SA, Lotze MT, Muul LM, Chang AE, Avis FP, et al. (1987) A progress report on the treatment of 157 patients with advanced cancer using lymphokine-activated killer cells and interleukin-2 or high-dose interleukin-2 alone. N Engl J Med 316: 889-897.

48. Shi J, Tricot G, Szmania S, Rosen N, Garg TK, et al. (2008) Infusion of haploidentical killer immunoglobulin-like receptor ligand mismatched NK cells for relapsed myeloma in the setting of autologous stem cell transplantation. $\mathrm{Br} \mathrm{J}$ Haematol 143: 641-653.

49. Miller JS, Soignier Y, Panoskaltsis-Mortari A, McNearney SA, Yun GH, et al. (2005) Successful adoptive transfer and in vivo expansion of human haploidentical NK cells in patients with cancer. Blood 105: 3051-3057.
50. Ma A, Koka R, Burkett P (2006) Diverse functions of IL-2, IL-15, and IL-7 in lymphoid homeostasis. Annu Rev Immunol 24: 657-679.

51. Berger C, Berger M, Hackman RC, Gough M, Elliott C, et al. (2009) Safety and immunologic effects of IL-15 administration in nonhuman primates. Blood 114: $2417-2426$

52. Klingemann HG (2005) Natural killer cell-based immunotherapeutic strategies. Cytotherapy 7: 16-22.

53. Mehta RS, Shpall EJ, Rezvani K (2015) Cord blood as a source of natural killer cells. Front Med (Lausanne) 2: 93.

54. Woll PS, Grzywacz B, Tian X, Marcus RK, Knorr DA, et al. (2009) Human embryonic stem cells differentiate into a homogeneous population of natural killer cells with potent in vivo antitumor activity. Blood 113: 6094-6101.

55. Knorr DA, Ni Z, Hermanson D, Hexum MK, Bendzick L, et al. (2013) Clinicalscale derivation of natural killer cells from human pluripotent stem cells for cancer therapy. Stem Cells Transl Med 2: 274-283.

56. Fujisaki H, Kakuda H, Shimasaki N, Imai C, Ma J, et al. (2009) Expansion of highly cytotoxic human natural killer cells for cancer cell therapy. Cancer Res 69: 4010-4017.

57. McKenna DH Jr, Sumstad D, Bostrom N, Kadidlo DM, Fautsch S, et al. (2007) Good manufacturing practices production of natural killer cells for immunotherapy: a six-year single-institution experience. Transfusion 47: 520-528.

58. Koehl U, Esser R, Zimmermann S, Tonn T, Kotchetkov R, et al. (2005) Ex vivo expansion of highly purified NK cells for immunotherapy after haploidentical stem cell transplantation in children. Klin Padiatr 217: 345-350.

59. Klingemann HG, Martinson J (2004) Ex vivo expansion of natural killer cells for clinical applications. Cytotherapy 6: 15-22.

60. Somanchi SS, Senyukov VV, Denman CJ, Lee DA (2011) Expansion, purification, and functional assessment of human peripheral blood NK cells. $\mathrm{J}$ Vis Exp.

61. Kim JV, Latouche JB, Riviere I, Sadelain M (2004) The ABCs of artificial antigen presentation. Nat Biotechnol 22: 403-410

62. Klein E, Ben-Bassat H, Neumann H, Ralph P, Zeuthen J, et al. (1976) Properties of the K562 cell line, derived from a patient with chronic myeloid leukemia. Int J Cancer 18: 421-431.

63. Maus MV, Thomas AK, Leonard DG, Allman D, Addya K, et al. (2002) Ex vivo expansion of polyclonal and antigen-specific cytotoxic $T$ lymphocytes by artificial APCs expressing ligands for the T-cell receptor, CD28 and 4-1BB. Nat Biotechnol 20: 143-148.

64. Numbenjapon T, Serrano LM, Singh H, Kowolik CM, Olivares S, et al. (2006) Characterization of an artificial antigen-presenting cell to propagate cytolytic CD19-specific T cells. Leukemia 20: 1889-1892.

65. Baggio L, Laureano AM, Silla LM, Lee DA (2017) Natural killer cell adoptive immunotherapy: coming of age. Clin Immunol 177: 3-11.

66. Pittari G, Fregni G, Roguet L, Garcia A, Vataire AL, et al. (2010) Early evaluation of natural killer activity in post-transplant acute myeloid leukemia patients. Bone Marrow Transplant 45: 862-871.

67. Lapteva N, Durett AG, Sun J, Rollins LA, Huye LL, et al. (2012) Large-scale ex vivo expansion and characterization of natural killer cells for clinical applications. Cytotherapy 14: 1131-1143.

68. Denman CJ, Senyukov VV, Somanchi SS, Phatarpekar PV, Kopp LM, et al. (2012) Membrane-bound IL-21 promotes sustained ex vivo proliferation of human natural killer cells. PLoS One 7: e30264.

69. Gong W, Xiao W, Hu M, Weng X, Qian L, et al. (2010) Ex vivo expansion of natural killer cells with high cytotoxicity by K562 cells modified to co-express major histocompatibility complex class I chain-related protein A, 4-1BB ligand, and interleukin-15. Tissue Antigens 76: 467-475.

70. Shah N, Martin-Antonio B, Yang H, Ku S, Lee DA, et al. (2013) Antigen presenting cell-mediated expansion of human umbilical cord blood yields logscale expansion of natural killer cells with anti-myeloma activity. PLoS One 8: e76781. 
71. Fujisaki H, Kakuda H, Imai C, Mullighan CG, Campana D (2009) Replicative potential of human natural killer cells. Br J Haematol 145: 606-613.

72. Cho D, Shook DR, Shimasaki N, Chang YH, Fujisaki H, et al. (2010) Cytotoxicity of activated natural killer cells against pediatric solid tumors. Clin Cancer Res 16: 3901-3909.

73. Zhang H, Cui $Y$, Voong N, Sabatino M, Stroncek DF, et al. (2011) Activating signals dominate inhibitory signals in CD137L/IL-15 activated natural killer cells. J Immunother 34: 187-195.
74. Singh H, Figliola MJ, Dawson MJ, Huls H, Olivares S, et al. (2011) Reprogramming CD19-specific T cells with IL-21 signaling can improve adoptive immunotherapy of B-lineage malignancies. Cancer Res 71: 35163527.

75. Liu Y, Wu HW, Sheard MA, Sposto R, Somanchi SS, et al. (2013) Growth and activation of natural killer cells ex vivo from children with neuroblastoma for adoptive cell therapy. Clin Cancer Res 19: 2132-2143.
This work was supported by the National Natural Science Foundation of China (No. 81372528) and the National High Technology Research and Development Program ("863" Program) of China (No. 2014AA020704). 